\title{
Impaired cerebral autoregulation in preoperative newborn infants with congenital heart disease
}

\author{
Jodie K. Votava-Smith, MD, ${ }^{a}$ Christopher J. Statile, MD, ${ }^{b}$ Michael D. Taylor, MD, PhD, ${ }^{b}$ \\ Eileen C. King, PhD, ${ }^{c}$ Jesse M. Pratt, MS, MA, ${ }^{c}$ David P. Nelson, MD, PhD, ${ }^{b}$ and Erik C. Michelfelder, MD $^{d}$
}

\section{ABSTRACT}

Objectives: To characterize cerebral autoregulation (CA) in preoperative newborn infants with congenital heart disease (CHD).

Methods: This was a prospective, pilot study of term newborns with CHD who required intensive care. Continuous mean arterial blood pressure (MAP), cerebral tissue oxygen saturation $\left(\mathrm{S}_{\mathrm{CT}} \mathrm{O}_{2}\right)$ via near-infrared spectroscopy, and arterial oxygen saturation $\left(\mathrm{SaO}_{2}\right)$ were collected. Significant low-frequency coherence between MAP and $\mathrm{S}_{\mathrm{CT}} \mathrm{O}_{2}$ was used to define impaired CA in 20-minute epochs. Cerebral fractional tissue oxygen extraction $(\mathrm{FTOE})=\left(\mathrm{SaO}_{2}-\mathrm{S}_{\mathrm{CT}} \mathrm{O}_{2}\right) / \mathrm{SaO}_{2}$ was calculated. Spearman's and rank bi-serial correlations and logistic linear models accounting for multiple measures were used to identify associations with impaired CA and coherence.

Results: Twenty-four term neonates were evaluated for $23.4 \pm 1.8$ hours starting the first day of life. Periods of $\mathrm{SaO}_{2}$ variability $>5 \%$ were excluded, leaving $63 \pm 10$ epochs per subject, 1515 total for analysis. All subjects demonstrated periods of abnormal CA, mean $15.3 \% \pm 12.8 \%$ of time studied. Significant associations with impaired CA per epoch included greater FTOE $(P=.02)$ and lack of sedation $(P=.02)$, and associations with coherence included greater FTOE $(P=.03)$, lack of sedation $(P=.03)$, lower MAP $(P=.006)$, and lower hemoglobin $(P=.02)$.

Conclusions: Term newborns with CHD display time-varying CA abnormalities. Associations seen between abnormal CA and greater FTOE, lack of sedation, and lower hemoglobin suggest that impaired oxygen delivery and increased cerebral metabolic demand may overwhelm autoregulatory capacity in these infants. Further studies are needed to determine the significance of impaired CA in this population. (J Thorac Cardiovasc Surg 2017;154:1038-44)

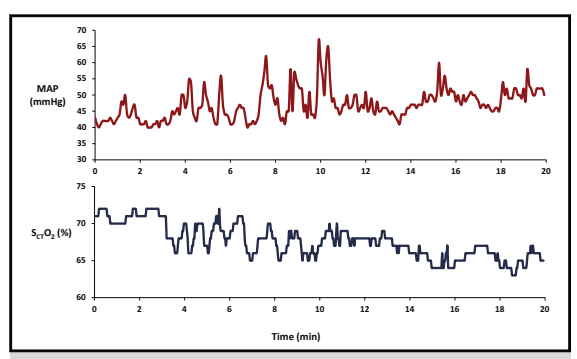

Impaired cerebral autoregulation: arterial pressure and cerebral blood flow vary together.

\section{Central Message}

Full-term newborn infants with severe forms of congenital heart disease display pressure passive cerebral perfusion in a spectrum similar to what has been described in premature newborns.

\section{Perspective}

This prospective pilot study found impaired cerebral autoregulation in preoperative infants with full-term congenital heart disease. Our findings highlight the importance of preoperative hemodynamic monitoring in a population of neonates known to have abnormalities of brain maturation and cerebral oxygen delivery, who are highly vulnerable to cerebral insult and neurodevelopmental impairment.

See Editorial Commentary page 1045.
Cerebral autoregulation (CA) is the body's normal process of regulating constant blood flow to the brain despite changing perfusion pressure. When $\mathrm{CA}$ is impaired, a change in

\footnotetext{
From the a Division of Cardiology, Department of Pediatrics, Children's Hospital Los Angeles, Los Angeles, Calif; ${ }^{b}$ Heart Institute, and ${ }^{c}$ Division of Biostatistics and Epidemiology, Cincinnati Children's Hospital Medical Center, Cincinnati, Ohio; and ${ }^{\mathrm{d}}$ Emory University School of Medicine, Sibley Heart Center Cardiology, Children's Healthcare of Atlanta, Atlanta, Ga.

Supported by a Novice Researcher Grant from the Gerber Foundation, awarded to J.K. Votava-Smith.

Received for publication Oct 4, 2016; revisions received April 24, 2017; accepted for publication May 10, 2017; available ahead of print June 17, 2017.

Address for reprints: Jodie K. Votava-Smith, MD, Children's Hospital Los Angeles, 4650 W. Sunset Blvd, MS\# 34, Los Angeles, CA 90027 (E-mail: jvotavasmith@ chla.usc.edu).

0022-5223/\$36.00

Copyright (c) 2017 by The American Association for Thoracic Surgery

http://dx.doi.org/10.1016/j.jtcvs.2017.05.045
}

blood pressure results in a parallel change in cerebral blood flow. Abnormalities of CA have been found in sick premature infants, ${ }^{1-5}$ a group at high risk for brain injury, and have been found to correlate with development of intracranial hemorrhage and mortality. , $^{2,7}$ Abnormal CA also has been linked adverse neurologic outcomes in newborns with hypoxic-ischemic encephalopathy and children with traumatic brain injury. 8,9 Cerebral oximetry via transcranial near-infrared spectroscopy (NIRS), which measures the tissue oxygen saturation of the brain, provides

Scanning this QR code will take you to a supplemental video for the article. 

Abbreviations and Acronyms
$\mathrm{CA}=$ cerebral autoregulation
$\mathrm{CHD}=$ congenital heart disease
$\mathrm{CI}=$ confidence interval
$\mathrm{ETCO}_{2}=$ end-tidal carbon dioxide $\begin{aligned} \text { FTOE }= & \text { cerebral fractional tissue oxygen } \\ & \text { extraction }\end{aligned}$
MAP $=$ mean arterial pressure
NIRS = near-infrared spectroscopy
$\mathrm{OR}=$ odds ratio
$\mathrm{SaO}_{2}=$ systemic arterial oxygen saturation
$\mathrm{S}_{\mathrm{CT}} \mathrm{O}_{2}=$ cerebral tissue oxygen saturation

a noninvasive surrogate of cerebral blood flow, ${ }^{10-13}$ and correlations between changes in continuous cerebral oximetry measurements during spontaneous fluctuations of blood pressure can be used to evaluate CA on a dynamic basis. ${ }^{2-4}$ Soul and colleagues ${ }^{3}$ studied low birth weight premature newborns using this technique and found that $97 \%$ of subjects had periods of impaired CA, with abnormalities seen during $20 \% \pm 10 \%$ of the time studied.

Full-term infants with congenital heart disease (CHD) have been shown to display findings of brain immaturity similar to those of premature infants, as well as patterns of preoperative brain injury and ischemia thought to be secondary to increased vulnerability of immature white matter, ${ }^{14-17}$ and may display neurologic abnormalities even before undergoing cardiac surgery. ${ }^{18}$ The reasons for neurologic insult in the CHD population are likely multifactorial, involving in utero fetoplacental circulation and genetic factors, as well as postnatal and perioperative insults secondary to unstable hemodynamics and medical interventions. Fetuses with severe forms of CHD have circulatory disturbances that alter oxygen and substrate delivery to the developing brain. ${ }^{19}$ Midgestation fetuses with CHD frequently demonstrate abnormal patterns of cerebral blood flow, including lower cerebrovascular resistance, which suggests an active process of CA to redirect blood flow towards the brain. ${ }^{20-22}$ Abnormalities of cerebral blood flow $^{23-25}$ and cerebral oxygen delivery $^{26}$ in neonates with CHD also have been found. Bassan and colleagues ${ }^{27}$ evaluated CA in infants less than 7 months of age with CHD after cardiac surgery and found disturbed CA in $51 \%$ of subjects on a fluctuating basis, with abnormalities seen during about $15 \%$ of the time studied. CA has not been studied in preoperative newborns with CHD. The aim of this study was to characterize CA in full-term newborn infants with unpalliated complex CHD and examine what factors are associated with disturbed CA. We hypothesized that full-term newborn infants with CHD would display impaired CA.

\section{METHODS}

This was a prospective, observational pilot study to evaluate CA in fullterm newborns with CHD. Eligibility criteria included infants with severe $\mathrm{CHD}$, defined as defects requiring admission to the Cardiovascular Intensive Care Unit at Cincinnati Children's Hospital Medical Center within the first 24 hours of postnatal life, between October 2011 and December 2012. Subjects were excluded if less than 36 weeks' gestational age, if major chromosomal abnormalities were found, and if they did not require a clinically indicated indwelling arterial catheter for continuous measurement of blood pressure. The study was approved by the Institutional Review Board at Cincinnati Children’s Hospital Medical Center (\#20111868), and informed consent was obtained.

Mean arterial pressure (MAP), measured via pressure transducer connected to an indwelling arterial catheter, and preductal systemic arterial saturation $\left(\mathrm{SaO}_{2}\right)$, measured from a pulse oximeter, were obtained as part of routine clinical care and were recorded continuously with a sampling frequency of $0.2 \mathrm{~Hz}$ with BedMasterEx software (Excel Medical Electronics, Jupiter, Fla). Cerebral oximetry was recorded with a FORESIGHT Absolute Oximeter with Small Dual Sensor (CAS Medical Systems, Inc, Branford, Conn). The FORE-SIGHT monitor uses laser light to project 4 wavelengths into the brain to calculate the absolute cerebral tissue oxygen saturation $\left(\mathrm{S}_{\mathrm{CT}} \mathrm{O}_{2}\right)$ with the ratio of oxygenated to total hemoglobin. The sensor was applied unilaterally to the forehead of the neonate and recorded continuously with a sampling frequency of $0.5 \mathrm{~Hz}$, timesynced to BedMasterEx file. Data were collected for up to 24 hours starting within the first 24 hours of life. Data were filtered for artifact and separated into 20-minute epochs of uninterrupted recordings for coherence analysis. Clinical care of the infants continued under the direction of the primary cardiovascular intensive care unit team without modification by investigators. Additional variables collected included continuous end-tidal carbon dioxide $\left(\mathrm{ETCO}_{2}\right)$, which was available only for intubated subjects, values of arterial blood gas and hemoglobin measurements obtained clinically during the study period, medications administered, presence and type of respiratory support, cardiac procedures which took place during the study period, cardiac and extracardiac diagnoses, results of preoperative brain imaging, chromosomal and microarray analysis when available, gestational age, delivery characteristics, Apgar scores, anthropomorphic data including height, weight, and head circumference.

Continuous data for each epoch were analyzed with custom software written in MatLab (MathWorks, Natick, Mass). $\mathrm{S}_{\mathrm{CT}} \mathrm{O}_{2}$ and MAP signals were detrended and normalized to remove DC signal. The $\mathrm{S}_{\mathrm{CT}} \mathrm{O}_{2}$ data were downsampled to $0.2 \mathrm{~Hz}$. Correlation was measured for each 20minute epoch using 10-minute windows and 50\% overlap using Welch's periodogram method, ${ }^{28}$ with coherence integrated for the very lowfrequency range of 0.003 to $0.04 \mathrm{~Hz}$ with a 1024 sample fast Fourier transform, and a coherence score was generated for each epoch. The coherence score describes the degree of correlation between the waveforms at a given frequency range. Minor fluctuations in blood pressure are expected even if the patient is stable, and with these fluctuations the $\mathrm{S}_{\mathrm{CT}} \mathrm{O}_{2}$ should not vary with MAP if CA is intact. Thus, coherence between $\mathrm{S}_{\mathrm{CT}} \mathrm{O}_{2}$ and MAP indicates impaired CA. Coherence of $1.0 \mathrm{in}$ dicates perfect correlation, and coherence of 0 indicates a complete lack of correlation.

By the use of an $\mathrm{F}$ test and the aforementioned parameters, the threshold for significant coherence for $P=.05$ was determined to be $0.58 .{ }^{29}$ Therefore, very low-frequency coherence $>0.58$ defined abnormal CA for our analysis. Examples of waveforms demonstrating high and low coherence are given in Figures 1 and 2. Cerebral fractional tissue oxygen extraction (FTOE) was calculated with the equation: FTOE $=\left(\mathrm{SaO}_{2}-\mathrm{S}_{\mathrm{CT}} \mathrm{O}_{2}\right) /$ $\mathrm{SaO}_{2}$. For each epoch the mean and standard deviation of MAP, $\mathrm{S}_{\mathrm{CT}} \mathrm{O}_{2}$, $\mathrm{SaO}_{2}, \mathrm{FTOE}$, and $\mathrm{ETCO}_{2}$ when available were calculated. Epochs with $\mathrm{SaO}_{2}$ variability $>5 \%$ were excluded from analysis to minimize the effect of varying $\mathrm{SaO}_{2}$ on $\mathrm{S}_{\mathrm{CT}} \mathrm{O}_{2}$. Percentage of epochs with abnormal CA (coherence $>0.58$ ) was calculated per patient. 

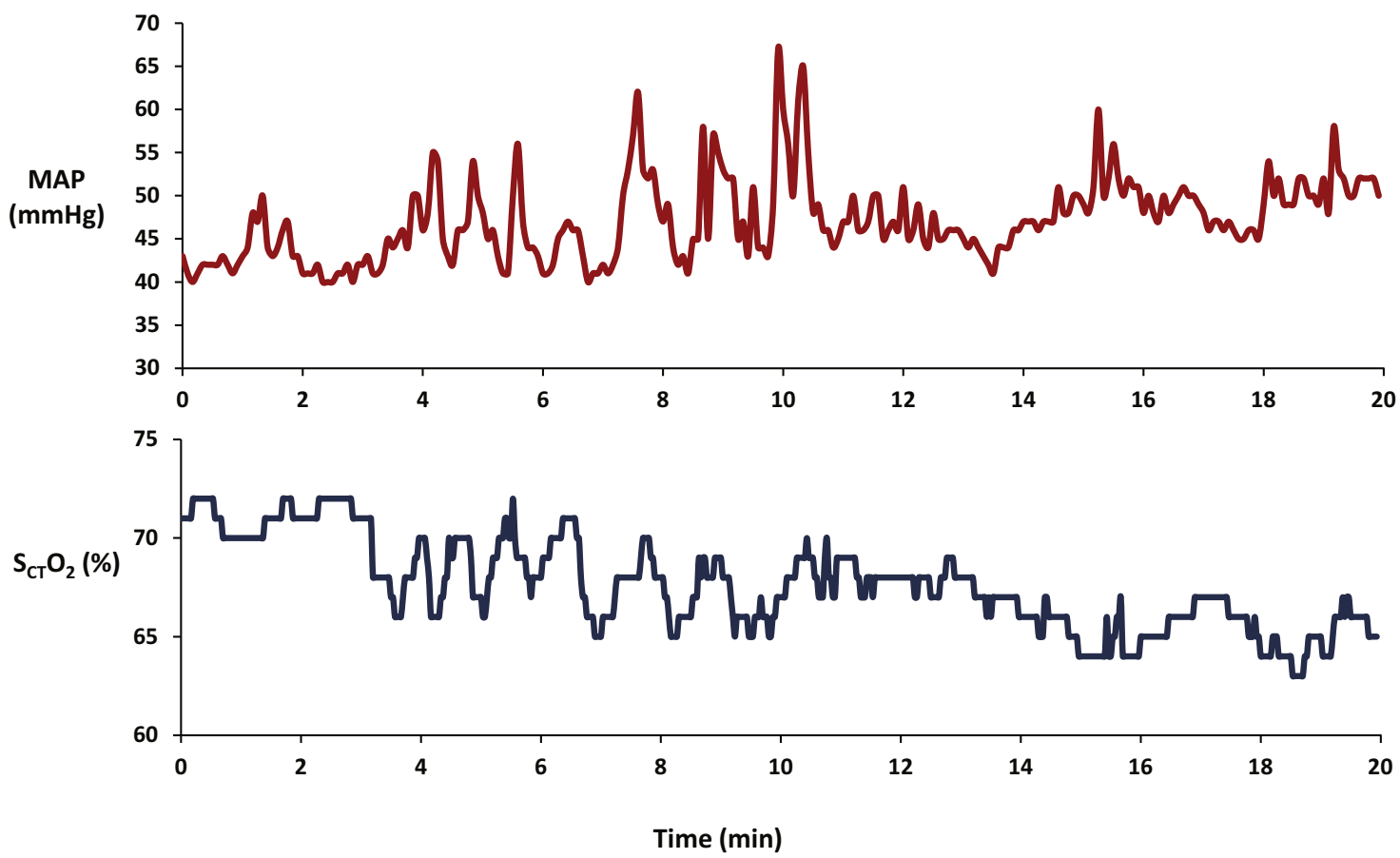

FIGURE 1. Example of MAP and $\mathrm{S}_{\mathrm{CT}} \mathrm{O}_{2}$ waveforms over an epoch with high coherence score of 0.89 , classified as impaired cerebral autoregulation. Changes in blood pressure on the top graph are mirrored by concomitant changes on the bottom graph. MAP, Mean arterial blood pressure; $\mathrm{S}_{C T} \mathrm{O}_{2}$, cerebral saturation.

Coherence was analyzed as a dichotomous measurement (normal, abnormal) and also as a continuous measurement. Generalized linear mixed effects models were run with the identity link and normal distribution for the continuous coherence measurement and the log link and binomial distribution for coherence categorized as normal/abnormal were used to identify significant predictors of coherence. A compound symmetry correlation structure was used to account for the correlation of measurements within each patient. Slopes and odds ratios (ORs) with

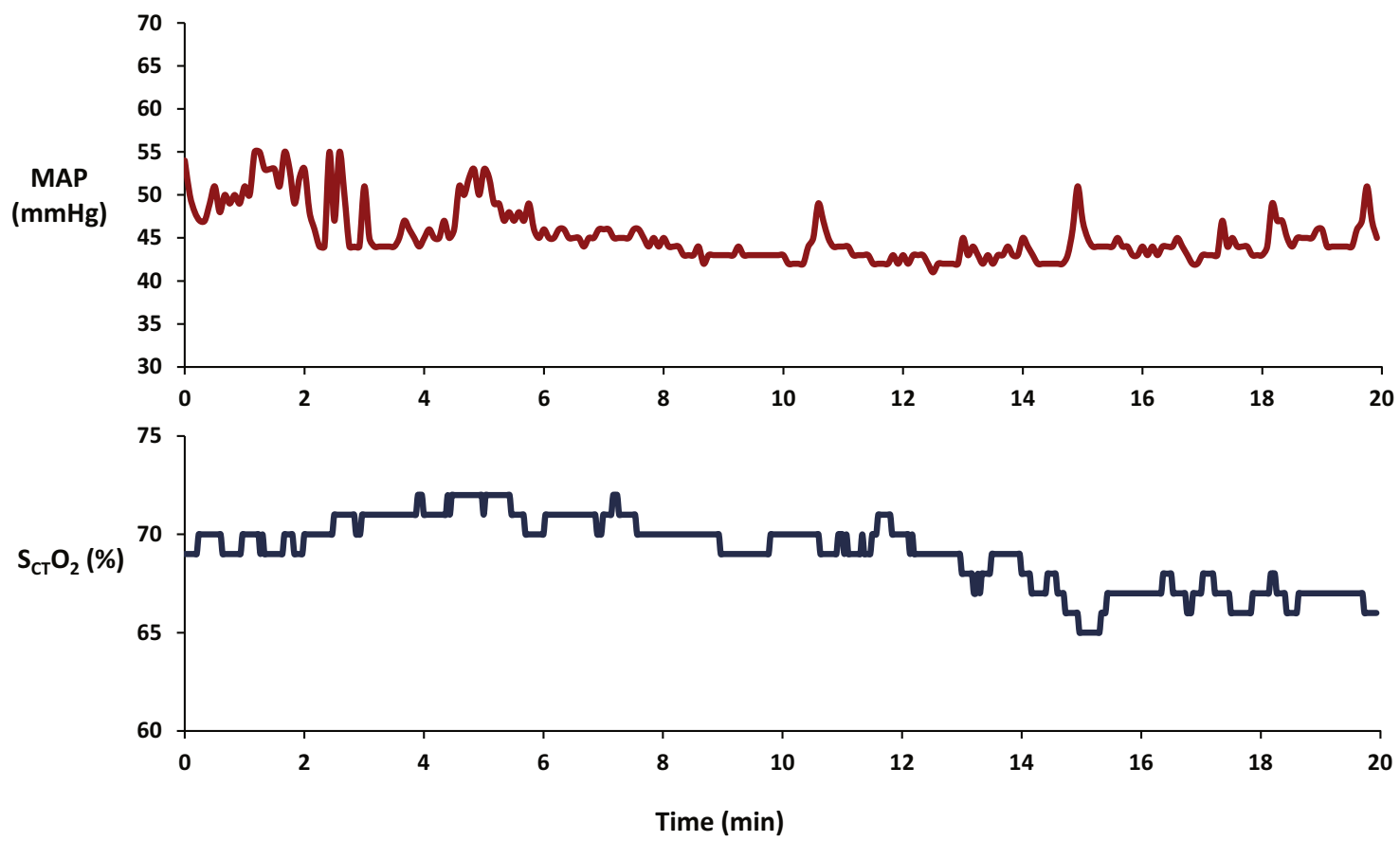

FIGURE 2. Example of MAP and $\mathrm{S}_{\mathrm{CT}} \mathrm{O}_{2}$ waveforms over an epoch with low coherence score of 0.19 , which was classified as intact cerebral autoregulation. Despite the changing MAP waveform in the top graph, the $\mathrm{S}_{\mathrm{CT}} \mathrm{O}_{2}$ waveform in the bottom graph remains relatively flat. MAP, Mean arterial blood pressure; $\mathrm{S}_{\mathrm{CT}} \mathrm{O}_{2}$, cerebral saturation. 
95\% confidence intervals (CIs) are presented for the predictors of coherence in each of the models.

Separate models were run with arterial blood gas values due to fewer observations for these predictors. Individual models were run for FTOE because of its dependence on $\mathrm{S}_{\mathrm{CT}} \mathrm{O}_{2}$ and $\mathrm{SaO}_{2}$. Spearman correlation coefficients were used to determine association between the percentage of epochs with abnormal CA and continuous individual subject variables, and the rank bi-serial correlation coefficient (Kendall's Tau) was used for dichotomous subject variables. ORs are interpreted as the odds of coherence being greater than 0.58 per unit increase in the model term. Slopes are interpreted as the change in coherence per unit increase in the model term. All statistical tests were conducted at $\alpha=0.05$. All analyses were performed with SAS, version 9.3 (SAS Institute Inc, Cary, NC).

\section{RESULTS}

A total of 28 infants completed data collection between October 2011 and December 2012. Four subjects were excluded from subsequent analysis, 2 because of extracorporeal membrane oxygenation support throughout analysis period, 1 because of a subsequent diagnosis of CHARGE syndrome (ie, coloboma, heart defects, choanal atresia, growth retardation, genital and ear abnormalities), and 1 because of normal cardiac anatomy on postnatal echocardiogram (after concern for coarctation of the aorta on prenatal echocardiogram). The remaining 24 infants comprised the study population. Subject demographics are given in Table 1. The congenital heart defects included 14 with limitation of systemic blood flow ( 8 with hypoplastic left heart syndrome, 3 single-ventricle variants with aortic stenosis and coarctation, and 3 with 2-ventricle hearts and coarctation of the aorta/Shone's complex, 2 of whom had significant mitral and aortic stenosis), 8 with limitation of pulmonary blood flow (6 single ventricle variants with pulmonary atresia, and 2 critical pulmonary stenosis with 2 -ventricles heart), and 2 with d-transposition of the great arteries. Seven subjects $(29 \%)$ had cardiac interventions before or during the study period, including 2 with

TABLE 1. Clinical characteristics of the study subjects $(\mathbf{N}=\mathbf{2 4})$

\begin{tabular}{lc}
\hline \multicolumn{1}{c}{ Subject characteristics } & $\begin{array}{c}\text { Mean } \pm \text { SD } \\
\text { or } \mathbf{n}(\%)\end{array}$ \\
\hline Gestational age at delivery, wk & $38.6 \pm 0.9$ \\
Male sex & $17(71)$ \\
Birth weight, kg & $3.25 \pm 0.43$ \\
Prenatal cardiac diagnosis & $22(92)$ \\
Vaginal delivery & $7(29)$ \\
Nonreassuring fetal heart tracings during delivery & $4(17)$ \\
5-min Apgar score & $8 \pm 1.4$ \\
Intubated in delivery room & $4(17)$ \\
Ventilator support during study period & $13(54)$ \\
Sedative medication during study period & $14(58)$ \\
Vasopressor/inotropic medication during study period & $10(42)$ \\
Prostaglandin infusion during study period & $24(100)$ \\
Single-ventricle cardiac defect & $16(67)$ \\
Cyanotic cardiac defect & $23(96)$ \\
\hline
\end{tabular}

$S D$, Standard deviation. pulmonary balloon valvuloplasty, 2 with balloon atrial septostomy, and 2 with atrial septal stent placements, although none had open heart surgery or cardiopulmonary bypass. Eighteen subjects had normal pre- or postnatal genetic analyses, 4 had no genetic analysis, and 2 had minor duplications of unclear clinical significance. All subjects had preoperative head ultrasounds; 20 were normal, 2 showed choroid plexus cysts, 1 had lenticulostriate vasculopathy, and 1 had echogenic choroid plexus versus mild grade 1 intraventricular hemorrhage, which was resolved on postoperative scan.

Subjects were studied for $23.4 \pm 1.8$ hours, with data collection beginning $7.5 \pm 3.8$ hours from birth. After exclusion of epochs with $\mathrm{SaO}_{2}$ variability $>5 \%$ (5.4\% of epochs), $63 \pm 10$ epochs per subject, 1515 total were available for analysis. All subjects were found to demonstrate periods of impaired CA, with mean $15.3 \% \pm 12.8 \%$ of epochs with abnormal CA, range of $3.5 \%-56.5 \%$. The results of the statistical analysis of impaired CA per subject (time spent with abnormal CA) compared with individual infant variables are given in Table 2. Gestational age, birth weight, and head circumference did not correlate with abnormal CA. Ventilator support was found to have a significant negative correlation such subjects who did not receive mechanical ventilation during the study had increased time with abnormal CA $(P=.04)$. Not receiving sedative medication had a borderline significant correlation coefficient $(P=.05)$.

All 1515 epochs were combined to analyze factors associated with impaired CA per epoch. This analysis was performed in 2 separate models, by assessing abnormal CA as a dichotomous variable, abnormal with coherence $>0.58$ or normal with coherence $<0.58$, and with the coherence as a continuous variable. Variables included values per epoch of mean MAP, $\mathrm{S}_{\mathrm{CT}} \mathrm{O}_{2}, \mathrm{SaO}_{2}, \mathrm{FTOE}$, and $\mathrm{ETCO}_{2}$, standard deviation of MAP, whether the epoch fell within the halflife of the subject receiving a sedative or inotropic medication, whether the subject was on mechanical ventilation, and the subject hemoglobin value within 12 hours. On univariate analysis, FTOE showed significant associations with abnormal CA per epoch with coherence as a dichotomous

TABLE 2. Associations between percentage of time with abnormal cerebral autoregulation and infant variables, evaluated per subject $(\mathbf{N}=\mathbf{2 4})$

\begin{tabular}{lcc}
\hline \multicolumn{1}{c}{ Infant variable } & Correlation coefficient $(\mathbf{r})$ & $\boldsymbol{P}$ value \\
\hline Gestational age & $-0.28^{*}$ & .19 \\
Birth weight & $0.04^{*}$ & .85 \\
Head circumference & $0.08^{*}$ & .71 \\
Inotrope use & $-0.33 \dagger$ & .06 \\
Sedative use & $-0.34 \dagger$ & .05 \\
Mechanical ventilation & $-0.36^{\dagger}$ & .04 \\
\hline
\end{tabular}

*Spearman’s correlation coefficient. †Rank bi-serial correlation. 
variable (OR 31.6; 95\% CI 1.8-544; $P=.02$ ) and with coherence as a continuous variable (slope $=0.14 ; 95 \%$ CI 0.02-0.26; $P=.03$ ); FTOE was not included in the multivariable models because of its dependence on $\mathrm{SaO}_{2}$ and $\mathrm{S}_{\mathrm{CT}} \mathrm{O}_{2}$. Results of the multivariable models are given in Table 3. The multivariable models demonstrated a significant association between impaired CA as a dichotomous variable and the infant not being on a sedative medication, and between higher coherence as a continuous variable and not being on a sedative medication, lower hemoglobin, and lower MAP. Inotrope usage was removed from the multivariable models because it was not a significant predictor in the univariate analyses $(P=.42$ for coherence $>0.58$ and $P=.50$ for coherence as continuous). Arterial blood gas values including $\mathrm{pH}$, partial pressure of carbon dioxide, partial pressure of oxygen, base excess, and lactate were analyzed by univariate analysis for the 149 epochs in which those blood tests were drawn; none had significant association with coherence $>0.58$ or with coherence as a continuous variable $(P>.15)$. $\mathrm{ETCO}_{2}$ was available for 751 epochs during which subjects were intubated and by univariate analysis was not associated with impaired CA $(P=.77)$ or coherence as a continuous variable $(P=.73)$. Average $\mathrm{ETCO}_{2}$ value for all epochs was $31.4 \pm 5.6$.

\section{DISCUSSION}

In this study, the first to evaluate CA in full-term preoperative newborn infants with CHD, we found fluctuating pressure passive cerebral perfusion in a spectrum similar to what has been described in premature newborns without CHD (Video 1). All subjects were studied within the first 2 days of life and although the range of time spent with abnormal CA was quite wide (3.5\%-57\%), abnormalities were seen in all subjects, and the mean time with abnormal CA of $15.3 \pm 12.8 \%$ was similar to that seen by Soul and colleagues $^{3}$ in very low birth weight premature infants, $19.6 \% \pm 11.4 \%$ on day 1 and $17.6 \% \pm 9.3 \%$ on day 2 , as well as that seen by Chock and colleagues ${ }^{30}$ in premature infants with hemodynamically significant patent ductus arteriosus, $9 \%-13 \%$.

When patient specific factors were evaluated, we found no associations with gestational age, birth weight, or head size. These findings differ from those seen in the premature population $^{3}$; however, we had little variability in these parameters, given inclusion of only subjects greater than 36 weeks' gestation. We found use of mechanical ventilation and sedatives to correlate with intact $\mathrm{CA}$ on a persubject basis, and in the combined analysis, sedative use to be associated with intact CA but ventilator use had no association. A tendency towards more intact $\mathrm{CA}$ in ventilated and sedated infants with CHD could explain the findings by Nagaraj and colleagues, ${ }^{24}$ who studied cerebral blood flow using arterial spin labeling on magnetic resonance imaging and found that preoperative neonates with CHD who had been ventilated previously had increased global and regional cerebral blood flow compared with nonventilated subjects with CHD. ${ }^{24}$ Effect of mechanical ventilation on $\mathrm{CO}_{2}$ levels also could explain its association with $\mathrm{CA}$; however, $\mathrm{ETCO}_{2}$ values for the 751 epochs on ventilated patients showed no correlation with abnormal CA. Although $\mathrm{CO}_{2}$ is known to have a cerebral vasodilatory effect and $\mathrm{CA}$ is reduced in states of hypercapnia, ${ }^{31}$ our average $\mathrm{ETCO}_{2}$ value for all epochs was $31.4 \pm 5.7$, thus relatively hypocapneic.

Individual arterial blood gas parameters showed no correlation with $\mathrm{CA}$, but these findings may have been hampered by small sample size of 149 epochs $(10 \%$ of total) with arterial blood gas values. Lower MAP was associated with greater coherence score, but values of $\mathrm{SaO}_{2}$ and $\mathrm{S}_{\mathrm{CT}} \mathrm{O}_{2}$ measured by NIRS were not. Overall, our MAP range was 33.3 to 70.9 for all epochs, and if a cut-off of $35 \mathrm{~mm} \mathrm{Hg}$ is used to define hypotension in a term neonate, ${ }^{32}$ fewer than $1 \%$ of all epochs would be classified as hypotensive. Thus, our findings suggest that fluctuating impaired CA exists in the term preoperative infant with CHD and can exist despite normotension, which highlights the importance of after cerebral in addition to systemic hemodynamics in this vulnerable population. Studies that use different techniques to quantify preoperative cerebral blood flow in the CHD population have found differing results $^{23-25}$; perhaps this could be explained by the fluctuating nature of $\mathrm{CA}$ seen in our study, in which abnormal CA was found to range from normal to impaired multiple times over the 24 -hour period studied. The cerebral

TABLE 3. Factors predicting abnormal cerebral autoregulation per epoch (all subject epochs combined); based on multivariable modeling

\begin{tabular}{|c|c|c|c|c|}
\hline \multirow[b]{2}{*}{ Epoch variable $(\mathrm{N}=1515)$} & \multicolumn{2}{|c|}{ Abnormal cerebral autoregulation based on coherence $>0.58$} & \multicolumn{2}{|c|}{ Coherence as continuous variable } \\
\hline & Odds ratio $(95 \%$ CI $)$ & $P$ value & Slope $(95 \%$ CI $)$ & $P$ value \\
\hline No sedative medication & $2.15(1.16-4.00)$ & .02 & $0.024(0.003-0.04)$ & .03 \\
\hline Hemoglobin, g/dL & $0.93(0.82-1.04)$ & .21 & $-0.006(-0.01,-0.0008)$ & .02 \\
\hline Mean MAP, mm Hg & $0.97(0.93-1.02)$ & .23 & $-0.002(-0.003,0.0006)$ & .006 \\
\hline MAP variability, $\mathrm{mm} \mathrm{Hg}$ & $1.08(0.91-1.29)$ & .38 & $-0.002(-0.008,0.005)$ & .55 \\
\hline Mean $\mathrm{S}_{\mathrm{CT}} \mathrm{O}_{2}$ & $0.97(0.93-1.01)$ & .09 & $-0.0013(-0.003,0.0002)$ & .09 \\
\hline Mean $\mathrm{SaO}_{2}$ & $1.04(0.02-1.09)$ & .07 & $0.0014(-0.0001,0.003)$ & .08 \\
\hline No mechanical ventilation & $1.39(0.02-87.8)$ & .50 & $0.012(-0.18,0.20)$ & .56 \\
\hline
\end{tabular}

$\mathrm{CI}$, Confidence interval; $\mathrm{MAP}$, mean arterial blood pressure; $\mathrm{S}_{\mathrm{CT}} \mathrm{O}_{2}$, cerebral tissue oxygen saturation; $\mathrm{SaO}_{2}$, systemic arterial oxygen saturation. 


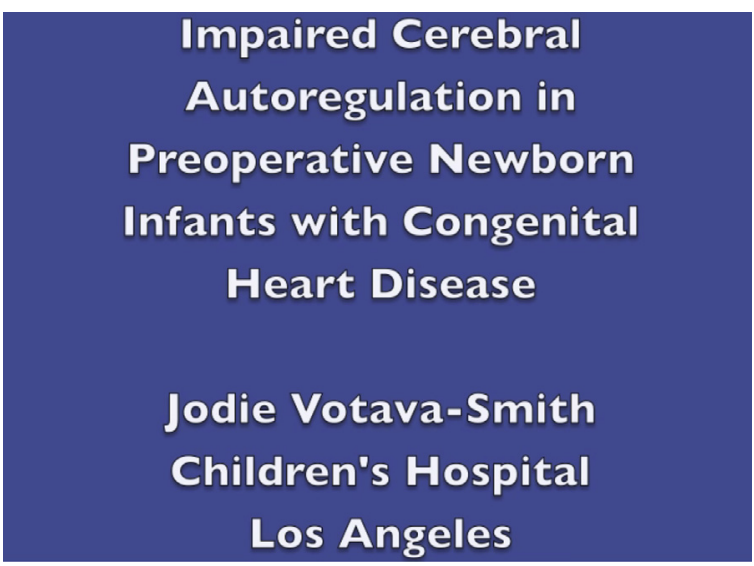

VIDEO 1. Dr Votava-Smith provides an overview of this study of cerebral autoregulation in preoperative newborn infants with congestive heart disease. Video available at: http://www.jtcvsonline.org/article/S0022-5223(17)310863/addons.

autoregulatory response relies on arterial vasodilation and vasoconstriction to accommodate for changes in perfusion pressure. Associations seen here between impaired CA and greater FTOE and lack of sedation suggest that impaired oxygen delivery and increased cerebral metabolic demand may overwhelm autoregulatory capacity in these infants. Given that prenatally, CHD fetuses frequently are seen to display evidence of middle cerebral artery dilation, suggesting an active process of $\mathrm{CA},{ }^{20-22}$ which has been associated with improved 18-month neurodevelopmental parameters, ${ }^{33}$ subjection to loss of CA in the postnatal environment may further stress an already-overtaxed cerebrovascular system. Greater fractional cerebral oxygen extraction in our study showed a correlation to impaired CA and may be an important parameter for assessment of cerebral hemodynamics in infants with cyanotic heart disease rather than NIRS trends alone.

Limitations of this study include the fact that our subject group had a wide variety of complex congenital cardiac defects, and subanalysis by cardiac lesion was not possible secondary to small sample size. However, all but one had cyanotic heart defects, defined as defects with significant intracardiac mixing of deoxygenated blood into the systemic output. The only noncyanotic subject consisted of a child with mild Shone's complex, coarctation of the aorta and ventricular septal defect, as the other 2-ventricle defects had significant aortic or pulmonary outflow obstruction or d-transposition of the great arteries. All subjects required prostaglandin infusion during the study period and all required neonatal surgical or catheter-based intervention. Of note, prostaglandin E-1 has been found to not affect dynamic CA in studies in adults and therefore should not have confounded our assessment. ${ }^{34}$ An additional limitation is the use of $\mathrm{S}_{\mathrm{CT}} \mathrm{O}_{2}$ measured by NIRS as a surrogate for cerebral blood flow. This has been validated by previous studies; however, it does require an assumption of stable cerebral metabolic rate and hemoglobin over the epoch; our analysis period of 20-minute epochs was the minimum possible based on our sampling interval, frequency range studied, and Fourier transform parameters. In addition, $\mathrm{S}_{\mathrm{CT}} \mathrm{O}_{2}$ does depend on the circulating oxygen delivered to the brain, such that $\mathrm{SaO}_{2}$ fluctuations could change the $\mathrm{S}_{\mathrm{CT}} \mathrm{O}_{2}$ for reasons other than cerebral perfusion. Although our subjects predominantly had cyanotic forms of CHD, because of the variety of $\mathrm{CHD}$ lesions studied, the relationship between changes in blood pressure and systemic saturations in our population is variable. We excluded epochs with variability of $\mathrm{SaO}_{2}$ more than $5 \%$ to minimize the effect of blood pressure changes causing parallel change in $\mathrm{S}_{\mathrm{CT}} \mathrm{O}_{2}$ independent of perfusion. We also assessed very low frequency coherence in a range of 0.003 to $0.04 \mathrm{~Hz}$, to specifically account with our frequency analysis the response time of the autonomic nervous system to result in a cerebral autoregulatory effect after a blood pressure change is seen. 3,35

An additional limitation is that our study did not have a control group. Because of the need for indwelling arterial catheter for continuous MAP assessment, we were not able to assess healthy term neonates with the methods described, for ethical and safety reasons. We did, however, have CA data on one subject who was enrolled based on prenatal concern for coarctation of the aorta, whose data were excluded from the analysis after findings of normal aortic arch and normal cardiac anatomy. This single normal subject was found to have $1 \%$ of time studied ( $1 / 71$ epochs) with abnormal CA, thus more intact CA than all of the subjects with CHD. Previous studies have demonstrated that abnormalities of CA in neonates vary with illness severity and presence of neurologic abnormality. 5,8,30 Future studies are warranted to potentially compare our results with "neurologically normal" groups of term neonates with clinically indicated arterial catheters, to explore noninvasive means of CA assessment that may allow for a healthy control group, and to expand our neonatal CHD recruitment to allow for CA assessment by cardiac lesion subtype and severity of illness.

In conclusion, this pilot study found that full-term preoperative neonates with severe forms of CHD display periodic impaired CA, even during times of normotension. These data contribute to a growing body of evidence regarding abnormalities of brain maturation, brain blood flow, and susceptibility to brain injury in neonates with CHD. Whether these abnormalities are related to disturbances in prenatal cerebral blood flow, oxygen or other substrate delivery, or potentially to genetic factors is unknown. Further studies currently are underway to determine whether disturbances of CA in the neonatal CHD population correlate with abnormalities of brain imaging on magnetic resonance imaging and outcomes such as subsequent neurodevelopmental impairment. 


\section{Conflict of Interest Statement}

Authors have nothing to disclose with regard to commercial support.

Dr Charles S. Kleinman was the initial driving force behind this study and was slated to be senior author but unfortunately did not live to see this work completed. His guidance and mentorship made this study possible.

\section{References}

1. Lou HC, Lassen NA, Friis-Hansen B. Impaired autoregulation of cerebral blood flow in the distressed newborn infant. J Pediatr. 1979;94:118-21.

2. Tsuji M, Saul JP, du Plessis A, Eichenwald E, Sobh J, Crocker R, et al. Cerebral intravascular oxygenation correlates with mean arterial pressure in critically ill premature infants. Pediatrics. 2000;106:625-32.

3. Soul JS, Hammer PE, Tsuji M, Saul JP, Bassan H, Limperopoulos C, et al. Fluctuating pressure-passivity is common in the cerebral circulation of sick premature infants. Pediatr Res. 2007:61:467-73.

4. Gilmore MM, Stone BS, Shepard JA, Czosnyka M, Easley RB, Brady KM. Relationship between cerebrovascular dysautoregulation and arterial blood pressure in the premature infant. J Perinatol. 2011;31:722-9.

5. Boylan GB, Young K, Panerai RB, Rennie JM, Evans DH. Dynamic cerebral autoregulation in sick newborn infants. Pediatr Res. 2000;48:12-7.

6. O'Leary H, Gregas MC, Limperopoulos C, Zaretskaya I, Bassan H, Soul JS, et al. Elevated cerebral pressure passivity is associated with prematurity-related intracranial hemorrhage. Pediatrics. 2009;124:302-9.

7. Wong FY, Leung TS, Austin T, Wilkinson M, Meek JH, Wyatt JS, et al. Impaired autoregulation in preterm infants identified by using spatially resolved spectroscopy. Pediatrics. 2008;121:e604-11.

8. Massaro AN, Govindan RB, Vezina G, Chang T, Andescavage NN, Wang Y, et al. Impaired cerebral autoregulation and brain injury in newborns with hypoxicischemic encephalopathy treated with hypothermia. J Neurophysiol. 2015;114: 818-24.

9. Vavilala MS, Muangman S, Tontisirin N, Fisk D, Roscigno C, Mitchell P, et al. Impaired cerebral autoregulation and 6-month outcome in children with severe traumatic brain injury: preliminary findings. Dev Neurosci. 2006;28:348-53.

10. Skov L, Pryds O, Greisen G. Estimating cerebral blood flow in newborn infants: comparison of near infrared spectroscopy and 133Xe clearance. Pediatr Res. 1991:30:570-3.

11. Tsuji M, duPlessis A, Taylor G, Crocker R, Volpe JJ. Near infrared spectroscopy detects cerebral ischemia during hypotension in piglets. Pediatr Res. 1998;44: $591-5$.

12. Soul JS, Taylor GA, Wypij D, Duplessis AJ, Volpe JJ. Noninvasive detection of changes in cerebral blood flow by near-infrared spectroscopy in a piglet model of hydrocephalus. Pediatr Res. 2000;48:445-9.

13. Brady KM, Lee JK, Kibler KK, Smielewski P, Czosnyka M, Easley RB, et al. Continuous time-domain analysis of cerebrovascular autoregulation using near-infrared spectroscopy. Stroke. 2007;38:2818-25.

14. Miller SP, McQuillen PS, Hamrick S, Xu D, Glidden DV, Charlton N, et al. Abnormal brain development in newborns with congenital heart disease. $N$ Engl J Med. 2007;357:1928-38.

15. Licht DJ, Shera DM, Clancy RR, Wernovsky G, Montenegro LM, Nicolson SC, et al. Brain maturation is delayed in infants with complex congenital heart defects. J Thorac Cardiovasc Surg. 2009;137:529-36; discussion 36-7.

16. Mahle WT, Tavani F, Zimmerman RA, Nicolson SC, Galli KK, Gaynor JW, et al. An MRI study of neurological injury before and after congenital heart surgery. Circulation. 2002;106:1109-14.

17. Beca J, Gunn JK, Coleman L, Hope A, Reed PW, Hunt RW, et al. New white matter brain injury after infant heart surgery is associated with diagnostic group and the use of circulatory arrest. Circulation. 2013;127:971-9.
18. Limperopoulos C, Majnemer A, Shevell MI, Rosenblatt B, Rohlicek C, Tchervenkov C. Neurodevelopmental status of newborns and infants with congenital heart defects before and after open heart surgery. J Pediatr. 2000; 137:638-45.

19. Sun L, Macgowan CK, Sled JG, Yoo SJ, Manlhiot C, Porayette P, et al. Reduced fetal cerebral oxygen consumption is associated with smaller brain size in fetuses with congenital heart disease. Circulation. 2015;131:1313-23.

20. Donofrio MT, Bremer YA, Schieken RM, Gennings C, Morton LD, Eidem BW, et al. Autoregulation of cerebral blood flow in fetuses with congenital heart disease: the brain sparing effect. Pediatr Cardiol. 2003;24:436-43.

21. Kaltman JR, Di H, Tian Z, Rychik J. Impact of congenital heart disease on cerebrovascular blood flow dynamics in the fetus. Ultrasound Obstet Gynecol. 2005; 25:32-6.

22. Modena A, Horan C, Visintine J, Chanthasenanont A, Wood D, Weiner S. Fetuses with congenital heart disease demonstrate signs of decreased cerebral impedance. Am J Obstet Gynecol. 2006;195:706-10.

23. Lynch JM, Buckley EM, Schwab PJ, McCarthy AL, Winters ME, Busch DR, et al. Time to surgery and preoperative cerebral hemodynamics predict postoperative white matter injury in neonates with hypoplastic left heart syndrome. J Thorac Cardiovasc Surg. 2014;148:2181-8.

24. Nagaraj UD, Evangelou IE, Donofrio MT, Vezina LG, McCarter R, du Plessis AJ, et al. Impaired global and regional cerebral perfusion in newborns with complex congenital heart disease. J Pediatr. 2015;167:1018-24.

25. Dehaes M, Cheng HH, Buckley EM, Lin PY, Ferradal S, Williams K, et al. Perioperative cerebral hemodynamics and oxygen metabolism in neonates with single-ventricle physiology. Biomed Opt Express. 2015;6:4749-67.

26. Lim JM, Kingdom T, Saini B, Chau V, Post M, Blaser S, et al. Cerebral oxygen delivery is reduced in newborns with congenital heart disease. J Thorac Cardiovasc Surg. 2016;152:1095-103.

27. Bassan H, Gauvreau K, Newburger JW, Tsuji M, Limperopoulos C, Soul JS, et al. Identification of pressure passive cerebral perfusion and its mediators after infant cardiac surgery. Pediatr Res. 2005;57:35-41.

28. Welch PD. Use of fast Fourier transform for estimation of power spectra-a method based on time averaging over short modified periodograms. IEEE Trans Audio Electroacoustics. 1967;15:70-3.

29. Taylor JA, Carr DL, Myers CW, Eckberg DL. Mechanisms underlying verylow-frequency RR-interval oscillations in humans. Circulation. 1998;98: $547-55$.

30. Chock VY, Ramamoorthy C, Van Meurs KP. Cerebral autoregulation in neonates with a hemodynamically significant patent ductus arteriosus. J Pediatr. 2012; 160:936-42.

31. Panerai RB, Deverson ST, Mahony P, Hayes P, Evans DH. Effects of $\mathrm{CO}_{2}$ on dynamic cerebral autoregulation measurement. Physiol Meas. 1999;20: 265-75.

32. Kitterman JA, Phibbs RH, Tooley WH. Aortic blood pressure in normal newborn infants during the first 12 hours of life. Pediatrics. 1969;44:959-68.

33. Williams IA, Fifer C, Jaeggi E, Levine JC, Michelfelder EC, Szwast AL. The association of fetal cerebrovascular resistance with early neurodevelopment in single ventricle congenital heart disease. Am Heart J. 2013;165: 544-50.e1.

34. Endoh H, Honda T, Ohashi S, Hida S, Shibue C, Komura N. The influence of nitroglycerin and prostaglandin E1 on dynamic cerebral autoregulation in adult patients during propofol and fentanyl anaesthesia. Anaesthesia. 2001;56: 947-52.

35. Panerai RB. Cerebral autoregulation: from models to clinical applications. Cardiovasc Eng. 2008;8:42-59.

Key Words: heart defects, congenital, cerebral autoregulation, coherence, neonate, pressure passive, near-infrared spectroscopy 